Ambiances

anbiances Environnement sensible, architecture et espace urbain Comptes-rendus | 2013

\title{
François Laplantine. Tokyo Ville Flottante: Scènes urbaines, mises en scène
}

\section{Anne Jarrigeon}

\section{OpenEdition}

\section{Journals}

Édition électronique

URL : http://journals.openedition.org/ambiances/128

DOI : 10.4000/ambiances. 128

ISSN : 2266-839X

\section{Éditeur :}

Direction Générale des Patrimoines - DAPA - MCC, UMR 1563 - Ambiances Architectures Urbanités (AAU)

\section{Référence électronique}

Anne Jarrigeon, «François Laplantine. Tokyo Ville Flottante : Scènes urbaines, mises en scène »,

Ambiances [En ligne], Comptes-rendus, mis en ligne le 05 février 2013, consulté le 22 septembre 2020

URL : http://journals.openedition.org/ambiances/128; DOI : https://doi.org/10.4000/ambiances.128

Ce document a été généré automatiquement le 22 septembre 2020.

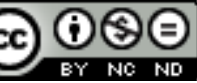

Ambiances is licensed under a Creative Commons Attribution-NonCommercial-NoDerivatives 4.0 International License. 


\section{François Laplantine. Tokyo Ville Flottante: Scènes urbaines, mises en scène}

Anne Jarrigeon

\section{RÉFÉRENCE}

Laplantine, François. 2010. Tokyo Ville Flottante : Scènes urbaines, mises en scène. Paris :

Stock.

1 «Ce livre n'est ni un ouvrage de spécialiste, ni un journal de voyageur. C'est un texte d'apprentissage ou plutôt de désapprentissage " avertit d'emblée François Laplantine (p.11). C'est pourtant bien à un voyage, esthétique et intellectuel, que nous invite cet anthropologue passionné et érudit. "Tokyo est une ville improbable qui rend une ethnographie classique incertaine ", souligne-t-il (p. 37). Sans tout à fait constituer une déclinaison empirique de son manifeste théorique pour une "anthropologie modale", Tokyo ville flottante semble servir d'expérimentation pour une pensée de la modulation qu'il appelle de ses vœux (Laplantine, 2005). La part ethnographique de l'ouvrage tient à un séjour prolongé à Tokyo au cours duquel François Laplantine a initié une confrontation de la description «des surfaces" avec ce qui dénomme «les horschamps de la fiction». Véritables "actes de résistance contre la violence de la généralisation et de l'abstraction", les démarches artistiques - littéraires et cinématographiques en particulier - et celle de l'ethnographie ont, selon lui, en commun le « souci de l'extrême précision » et « des singularités concrètes » (p. 31). La littérature et le cinéma viennent ici en « contrepoints » des observations in situ, et font sortir l'observateur de ce que la société japonaise montre d'elle-même. Ils rendent possible une «exploration latérale » des «scènes urbaines" au sens goffmanien du terme (p. 86). 
2 Dans ce livre à la construction peu classique - deux parties composent en effet les actes de ce jeu entre les scènes de rue et les innombrables mises en scènes esthétiques auxquelles a donné lieu Tokyo - François Laplantine cherche à restituer par petites touches, ajustements constants et interprétations subtiles les « contradictions ou plutôt les oscillations" et les "modulations sensibles" de la capitale japonaise (p. 88). Il multiplie les échelles d'observation et les points de vue et déploie son habituel talent d'écriture pour rendre compte de Tokyo, qu'il qualifie de ville "métallique», « iconique », soustraite à la symétrie et à la structure, «visuellement saturée » et dont la densité s'accorde pourtant avec une certaine fluidité voire une "décontraction». D'après François Laplantine, ces contrastes produisent une « ambiance enveloppante », "fluctuante", "instable», une atmosphère presque "liquide " selon le terme qu'il emprunte à Bauman (Bauman, 2006) et dont il fait, par la convocation articulée de multiples références artistiques et théoriques, une caractéristique de la culture japonaise.

3 Les impressions évanescentes des débuts, celles liées à la sonorité de la langue, à la perception des rythmes de la foule, aux mouvements corporels dans les rues de Tokyo se précisent dans la description de situations urbaines singulières. François Laplantine prête la même attention minutieuse aux enchevêtrements de fils électriques qu'aux agencements des jardins, aux vêtements extravagants des jeunes filles à la station Shibuya qu'aux attitudes des citadins assistant dans le parc Yoyogi au lent rougissement des feuilles d'érable à l'automne. Il aborde la culture japonaise sous toutes ses formes, populaires et savantes. C'est d'ailleurs un des grands bonheurs de la lecture de ce livre qui nous plonge tour à tour dans la littérature et la peinture de l'époque Edo, dans l'art traditionnel des bonzaïs ou de l'ikebana (composition florale), nous présente la création plastique contemporaine, les émanations popku de la culture kawai que ne recouvre pas l'univers des otaku abordé comme un "nouvel existentialisme japonais». François Laplantine nous fait passer en quelques paragraphes des travestissements du théâtre Nô à ceux du cosplay (costume playing), de Hokusai à Abe, de Osu à Kitano, de Murakami à Hello Kitty, dessinant un parcours éclectique et entrainant, au service d'un questionnement réflexif sur les cultures contemporaines et leurs rapports au monde.

4 Méditation philosophique impulsée par un décentrement sans le dépaysement radical associé ici à la découverte de la culture chinoise, ce livre propose un détour expérimental et documenté par la pensée orientale pour interroger le système occidental. Au risque d'un essentialisme culturel ponctuel dont il dénonce pourtant la « tentation » catalysée par la « singularité nippone », François Laplantine fait travailler pour sa propre théorie les conceptions de la nature, du temps et de l'espace d'une culture qualifiée de "non-théoricienne » voire de "non-théorique » et capable d'une «suspension momentanée du langage » qu'il semble admirer.

5 Le connaisseur du Japon puisera dans la lecture de ce livre des réflexions aiguisées et une invitation à lire et relire, voir et revoir des œuvres évoquées avec le plus grand soin. Le néophyte y trouvera une magnifique introduction à la culture sensible et à la pensée japonaise servie par une très grande liberté de ton, caractéristique de cet anthropologue à l'insatiable curiosité. 


\section{BIBLIOGRAPHIE}

Bauman, Zygmunt (2006). La vie liquide. Rodez : Le Rouergue - Chambon.

Laplantine, François (2005). Le social et le sensible. Introduction à une anthropologie modale. Paris : Téraèdre.

\section{AUTEURS}

\section{ANNE JARRIGEON}

Anne Jarrigeon est anthropologue et maître de conférences en urbanisme à l'Université Paris Est, Laboratoire Ville Mobilité Transport. Ses recherches actuelles, à la croisée de l'ethnologie urbaine, de la sémiotique et de l'anthropologie visuelle, portent sur l'expérience des mobilités quotidiennes, entre pratique des dispositifs et des lieux, interactions sociales et perceptions spatiales.

anne.jarrigeon@univ-paris-est.fr 